\title{
USING THE BETA DISTRIBUTION \\ FOR ASSESSMENT OF AVAILABILITY AND \\ RELIABILITY OF TECHNICAL TRANSPORT \\ FACILITIES
}

\section{WYKORZYSTANIE ROZKLADU BETA \\ DO OCENY GOTOWOŚCI I NIEZAWODNOŚCI \\ TECHNICZNYCH SYSTEMÓW TRANSPORTOWYCH}

\section{Zbigniew Smalko, Jerzy Jaźwiński}

Air Force Institute of Technology

Warsaw

\begin{abstract}
The paper presents the properties of normalized and generalised beta distributions. Possibility of the use of beta distributions to estimate the reliability and safety of technical transport systems is presented. Suggested is an approach to a method of supplementing the inadequate information with data generated in statistical investigation on the grounds of expert estimates employed for estimating the parameters of beta distributions .
\end{abstract}

Keywords: beta distribution, reliability, safety, transport systems

Streszczenie: W pracy omówiono właściwości znormalizowanego i uogólnionego rozkładu beta. Przedstawiono możliwość stosowania rozkładów beta do szacowania niezawodności i bezpieczeństwa technicznych systemów transportowych. Zaproponowano pewien sposób podejścia do metody uzupełniania niepełnych informacji danymi wygenerowanymi w trakcie badań statystycznych na bazie eksperckich szacunków zastosowanych do szacunkowej oceny parametrów rozkładów beta.

Słowa kluczowe: rozkład beta, niezawodność, bezpieczeństwo, systemy transportowe 


\section{Introduction}

The technical transport systems in their operation processes feature many various properties and qualities which can be described by means of random variables or processes Their physical and technical premises indicate that these random variables are bound at both sides (Jaźwiński, Smalko 1996). The times of recovery, state control, performance of various stages of operation task, and performance of various control operations are limited. The authors have analysed this problem to conclude that the beta distribution could be employed as an adequate distribution model which could be accepted as a good approximation of the distribution of bound random variables. Let us discuss a number of examples of random variables that describe such operating situations where the beta distribution could be applied.

The recovery time in systems of high complexity is bound - at its greatest lower side - by the times necessary for organizing, fault finding, and faulty part removing and replacing purposes. The repair time determines the least upper bound recovery time. . The repair time for the plants (machines) that fail most often determines the modal value of the recovery time distribution and this situation affects the amount of distribution skewness too. A positive type skewness occurs usually in case of recovery.

A minimum operation time depends on the minimum elementary operation times. The necessity of removal of the faults found in maintenance procedure results in operation time spread. A positive type skewness occurs in case of operations procedures.

A minimum work resource for the operation performed according to the work resource depends on removal of faultiness' of the plant subassemblies in the post-production quality assurance control. The maximum work resource is determined by appropriate regulations. A negative type skewness occurs in this case.

The models of wear and tear process distributions can be defined by means of beta distribution in many cases. These distributions in case of operation according to work resources could be approximated by means of symmetrical or unsymmetrical beta distributions (Jaźwiński, Smalko 2000).

\section{Formulation of the problem}

The specialists concerned with technical transport facilities observe various events and, among other things, such as the following:

- failure of the transport facility in situations where a transport task is executed; 
- occurrence of an accident premise in situations where a transport task is executed;

- occurrence of an accident;

- a fault has been found during the operating condition inspection procedure;

- various operation procedures have been executed on time, or time scheduled has not kept.

Basing on statistical information obtained from experiments it is possible to estimate the distribution parameters for various random events and variables taking place in operation process ( Bobrowski 1985).

In practice, it is rather difficult to observe a great number of events such as accidents, accident premises related to individual subassemblies, failures of some assemblies and set-ups, and therefore statistical investigations do not provide information that is necessary for complex reliability analysis. Thus, we try to supplement this incomplete data set by employing the expert method.

The performed analyses prove that the beta distribution is a suitable mathematical tool to estimate the subjective probability of such events. Beside providing a more precise characteristics of this distribution, the paper advisees possible determination of beta distribution parameters on the grounds of expert estimates.

\section{Beta distribution characteristics}

The importance of model building with the use of generalised and normalized beta distributions for dangerous situations are in general not appreciated (Jaźwiński, Smalko, Żurek 2000). Thus, it seems to be purposeful to present the properties taking account of the advantages of this distribution (refer to Fig. 1).

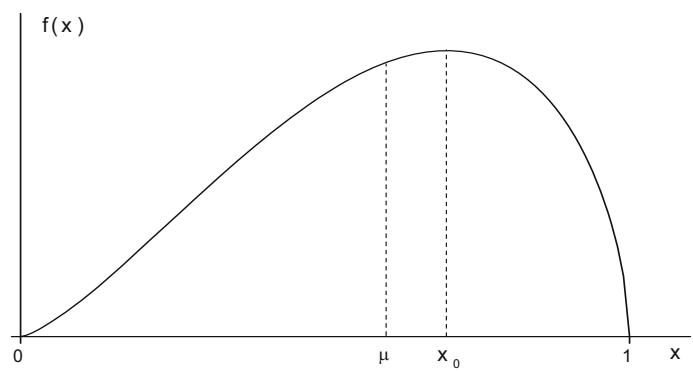

Fig.1. Selected form of probability density for the standardised beta distribution. 
A beta distribution of the first kind that is defined by means of normalized two-parameter probability density $f(x, \alpha, \beta)$ and expressed by the following formula (Nill, Clayton 1966) is usually employed:

$$
f(x ; \alpha, \beta)= \begin{cases}\frac{(\alpha+\beta+1) !}{\alpha ! \beta !} x^{\alpha}(1-x)^{\beta}, & 0<x<1, \\ & \alpha>-1, \\ & \beta>-1, \\ 0 \quad \text { in the remaining cases } & \end{cases}
$$

where: $f(x ; \alpha, \beta) \quad$ - probability density function [PDF],

$\begin{array}{ll}\alpha, \beta & \text { - distribution parameters, } \\ 0 & \text { - greatest lower bound of the feature } X, \\ 1 & \text { - least upper bound of the feature } X .\end{array}$

The beta distribution is recognized as one that belongs to the class of most flexible probability distributions bound at both its sides (Bobrowski 1985). This assumption results in limitation of the given-phenomenon observation time to a certain finite interval. However, even if this bound is true various distribution curves are likely as these depend on the parameters $\alpha$ and $\beta$.

By providing these parameters, the shape of the curve can be defined. However, the parameters do not have direct physical interpretation. But it can be stated that the ratio of the parameters $\alpha$ and $\beta$ is equal to the ratio of the sections into which the modal value divides the finite interval [0,1], i.e. the distribution span:

$$
\frac{\alpha}{\beta}=\frac{x_{0}}{1-x_{0}},
$$

where: $\alpha, \beta$-distribution parameters,

$x_{0} \quad$ - modal value of $X$.

The position parameter, i.e. the modal value, plays a particular role in the beta distribution. The ratio of distribution parameters $\alpha / \beta$ varies with position of the modal value in the interval determined by its span $[0,1]$. Refer to Fig.2.

The basic characteristics of normalized beta distribution can be presented in the following way (Nill, Clayton 1966).

The modal value (mode) can be defined by:

$$
x_{0}=\frac{\alpha}{\alpha+\beta} \text {. }
$$




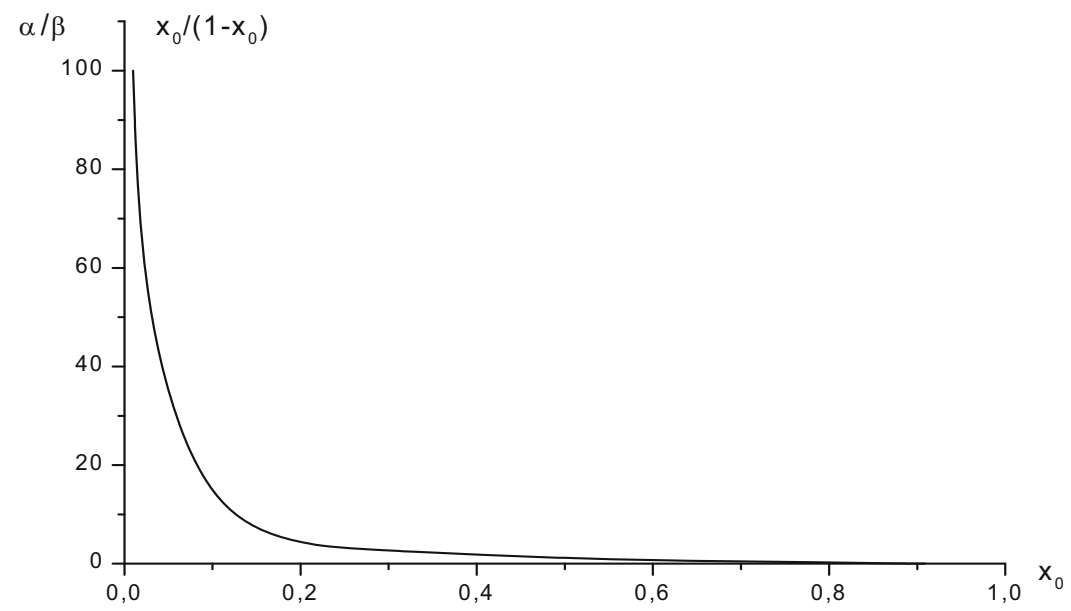

Fig. 2. Variation of the ratio of parameters $\alpha / \beta$ according to the modal value $x_{0}$.

The skewness factor defined by the following formula is also an important feature:

$$
\alpha_{3}=\frac{2(\beta-\alpha)}{\alpha+\beta+4} \sqrt{\frac{\alpha+\beta+3}{(\alpha+1)(\beta+1)}} .
$$

The distribution skewness depends on the values taken on by the parameters $\alpha$ and $\beta$ in the following way:

$$
\begin{array}{ll}
\alpha=\beta, & \alpha_{3}=0 \\
\alpha<\beta, & \alpha_{3}>0 \\
\alpha>\beta, & \alpha_{3}<0 .
\end{array}
$$

Thus, the modal value $\mathrm{x}_{0}$ and the skewness factor $\mathrm{a}_{3}$ have the fundamental influence on the form of beta distribution.

The remaining more important features of the beta distribution are as follows:

Mean value: $\quad \eta=\frac{\alpha+1}{\alpha+\beta+2}$,

Variance:

$$
\sigma^{2}=\frac{(\alpha+1)(\beta+1)}{(\alpha+\beta+2)^{2}(\alpha+\beta+3)}
$$

Third central moment: $\mu_{3} \frac{2(\alpha+1)(\beta+1)(\beta-\alpha)}{(\alpha+\beta+4)(\alpha+\beta+3)(\alpha+\beta+2)^{3}}$, 
Fourth central moment:

$\mu_{4}=\frac{3(\alpha+1)(\beta+1)}{(\alpha+\beta+1)(\alpha+\beta+3)(\alpha+\beta+2)^{3}}\left[\frac{(\alpha+2)(-\alpha+2 \beta+1)}{\alpha+\beta+5}+\frac{(\alpha+1)(\alpha-\beta)}{\alpha+\beta+2}\right]$

Coefficient of variation: $\quad \eta=\sqrt{\frac{\beta+1}{(\alpha+1)(\alpha+\beta+3)}}$

Excess factor:

$$
\alpha_{4}=\frac{3(\alpha+\beta+2)(\alpha+\beta+3)}{(\alpha+\beta+1)(\alpha+1)(\beta+1)}\left[\frac{(\alpha+2)(-\alpha+2 \beta+1)}{\alpha+\beta+5}+\frac{(\alpha+1)(\alpha-\beta)}{\alpha+\beta+2}\right] .
$$

While estimating the operation characteristics such as e.g., failure-proneness (unreliability) function and failure-freedom (reliability) function as well as failure rate function the discussion is to be bound to those cases where the distribution parameters are positive ones, i.e. $\alpha, \beta>0$.

Selected characteristics of the beta distribution for a random variable $\mathrm{T}$ that describes the operation time for plants are shown in Fig. 3 (Nill, Clayton 1966).
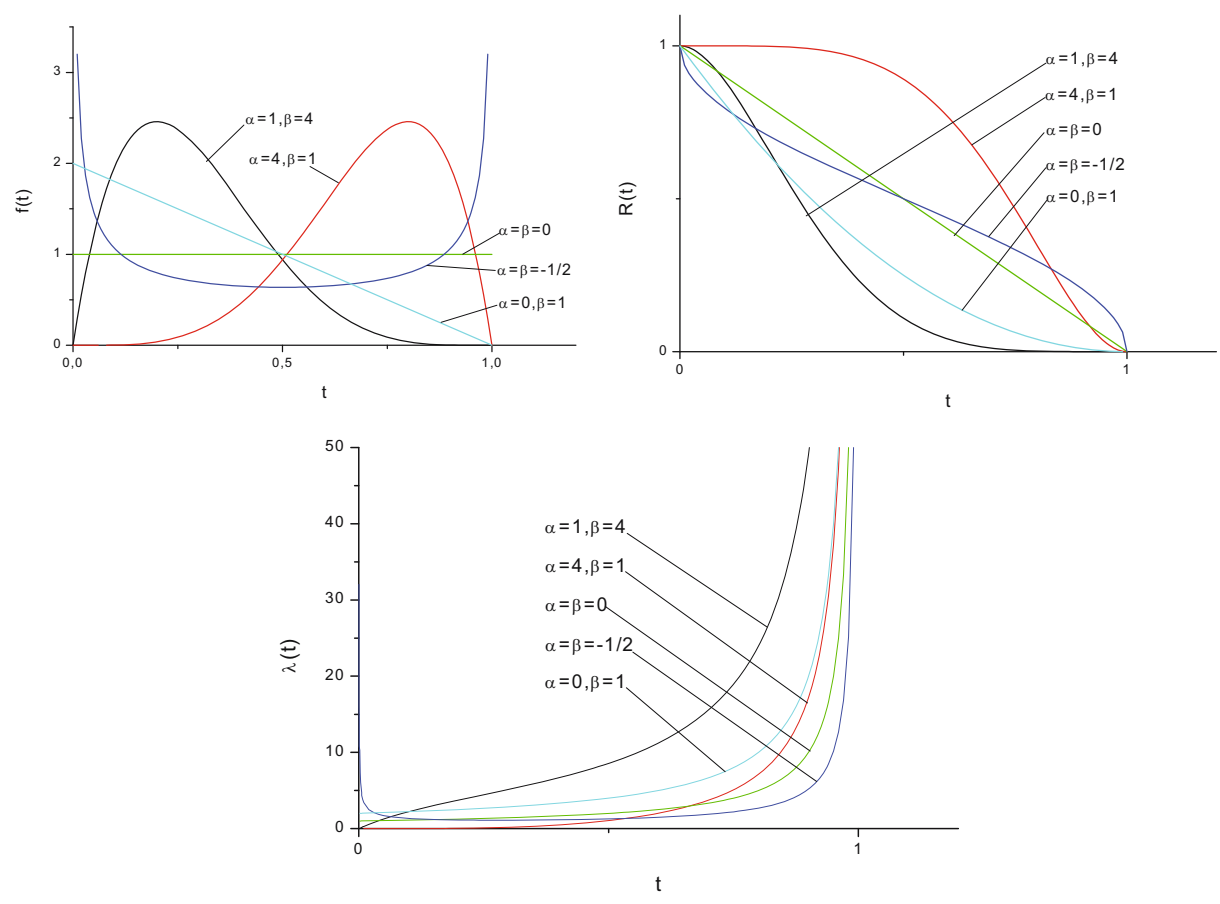

Fig.3. Examples of functions $f(t), R(t)$ and $\lambda(t)$. 
The failure -freedom (reliability) function (complement of distribution function) $R(t)$ has the following form:

$$
R(t)=\left\{\begin{array}{l}
1, \quad t \leq 0 \\
\int_{t}^{1} \frac{(\alpha+\beta+1) !}{\alpha ! \beta !} x^{\alpha}(1-x)^{\beta} d x, \quad 0 \leq t \leq 1,
\end{array}\right.
$$

The failure rate $\lambda(\mathrm{t})$ can be expressed in the following way:

$$
\lambda(t)= \begin{cases}0 & t \leq 0, \\ \frac{t^{\alpha}(1-t)^{\beta}}{\int_{t}^{1} x^{\alpha}(1-x)^{\beta} d x} & 0<t<1, \\ 0 & t \geq 1\end{cases}
$$

where:

$t \quad$ - life of the plant under discussion,

$f(t)$-failure probability density,

$R(t)$ - failure -freedom function,

$\lambda(t)$ - failure rate.

Mentioned above are major features of the normalized beta distribution from the reliability and safety point view.

\section{Employing the expert method to estimate the parameters of beta distribution}

In practice, it is rather difficult to observe a great number of events such as aircraft accidents, aircraft-accident premises (related to individual subassemblies), and therefore statistical investigations cannot provide information that is necessary. Thus, we try to supplement this incomplete information by employing the expert method to estimate the parameters of generalised beta distribution.

Let us discuss some properties of generalised beta distribution (Nill, Clayton 1966), (Bobrowski 1985) to create more convenient conditions for carrying out the expert estimation. Refer to Fig. 5. 


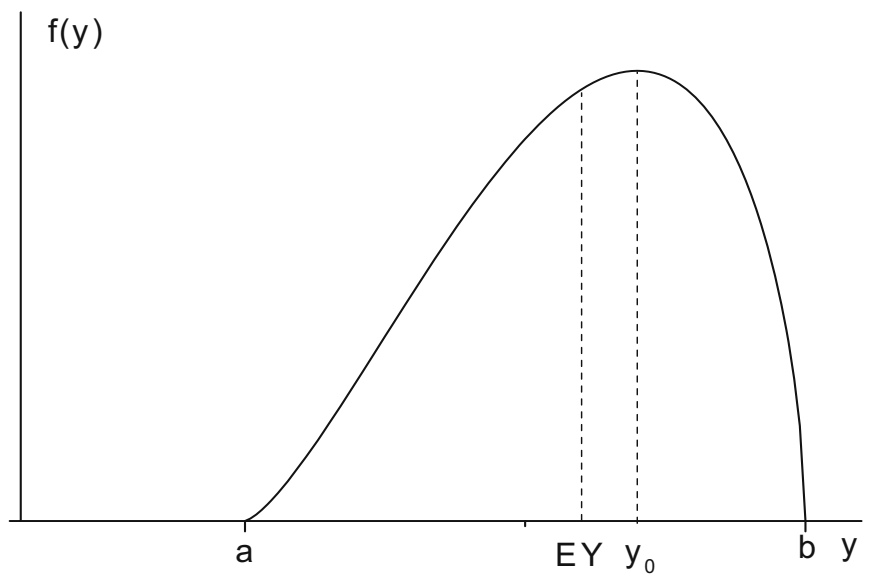

Fig.5. Form of probability density for a generalised beta distribution.

The generalised distribution density for a beta distribution is expressed in the following way:

$$
f(y, \alpha, \beta, a, b)= \begin{cases}\frac{(\alpha+\beta+1) !}{\alpha ! \beta !(b-a)^{\alpha+\beta-1}}(y-a)^{\alpha}(b-a)^{\beta}, & a<y<b \\ 0 \quad \text { in the remaining cases } & b>a, a \neq 0,\end{cases}
$$

where:

$a$ - greatest lower bound of the feature $Y$,

$b$ - least upper bound of the feature $Y$.

This function is defined for any positive difference of $b-a>0$. As $a$ can be any real number, the distribution can be scattered in any finite interval $[a$, b].

The transformation of random variable $\mathrm{Y}$ into a random variable $\mathrm{X}$ may be performed with the following relationship taken into consideration (Nill, Clayton 1966):

$$
X=\frac{Y-a}{b-a}
$$


While expert investigation is performed, defined values are assigned to the position parameters of the probability distribution.

The greatest lower bound $a$ of the distribution can be understood as e.g. a pessimistic availability time, while the least upper bound $b$ of the distribution -optimistic availability time. And the modal value $\mathrm{y}_{0}$ is understood as the most likely availability time.

According to the theory of decision-making under uncertainty conditions, the $\mathrm{i}$-th expert $(\mathrm{i}=1,2, \ldots, \mathrm{n})$ provides a pessimistic $a_{i}$, the most likely $\mathrm{y}_{\mathrm{oi}}$ and an optimistic $b_{i}$ estimations for the given random variable $\mathrm{Y}$, say, the machine life.

The expected value of the random variable Y can be defined by:

$$
E Y=\frac{a(1+\beta)+b(1+\alpha)}{(1+\beta)+(1+\alpha)},
$$

and the modal value (mode) can be presented in the following way:

$$
y_{0}=\frac{\alpha}{\alpha+\beta}
$$

The relationship of the parameters $\alpha / \beta$ in a generalised beta distribution can be presented identically as in expression (2) :

$$
\frac{\alpha}{\beta}=\frac{y_{0}-a}{b-y_{0}} \text {. }
$$

The expert estimates are subject to analysis where the greatest lower bound ( $\min a$ ) and least upper bound ( $\max b$ ) estimates of the feature $\mathrm{Y}$ are taken to calculate the parameters $y_{0}$ and $\gamma$.

The modal value is estimated on the grounds of expert data in the following way:

$$
y_{0}=\frac{1}{n}\left(\gamma \underline{y}_{0}+\xi y_{0}+\omega \bar{y}_{0}\right), \quad \gamma+\xi+\omega=n
$$

where:

$n \quad$ number of expert data values,

$\zeta \quad$ number of the most often occurring realizations of random variable $X$,

$\gamma, \varpi \quad$ numbers of estimates contiguous at both sides to the most often occurring value of random variable $Y$, respectively. 
The expected value EY is calculated on the grounds of distribution series made of all the estimates of the feature value $Y$, from the following formula:

$$
\mathrm{EY}=\frac{1}{n-1}\left(\sum_{i=1}^{n} a_{i}+\sum_{i=1}^{n} b_{i}+\sum_{i=1}^{n} y_{o i}\right), \quad i=1,2, \ldots, n
$$

where:

$a_{i}$ - estimate provided by the $i$-th expert for the greatest lower bound of the feature $Y$,

$b_{i}$ - estimate provided by the $i$-th expert for the least upper bound of the feature $Y$, $y_{o i}$-estimate provided by the $i$-th expert for the modal value of the feature $Y$ $n$ - number of experts (expertises).

Having the least and greatest bound, modal and mean estimated of the feature value $\mathrm{Y}$ we can calculate the values of parameters $\alpha i \beta$ from the formulae presented below:

$$
\begin{gathered}
\alpha=\frac{\bar{y}_{0}-a}{\mathrm{EY}-\bar{y}_{0}}-\frac{a+b-2 \mathrm{EY}}{b-a}, \\
\beta=\frac{b-\bar{y}_{0}}{\bar{y}_{0}-a} \alpha
\end{gathered}
$$

Familiarity with these parameters enables you to define both generalised and normalized forms of subjective probability density. Refer to Fig. 6. 


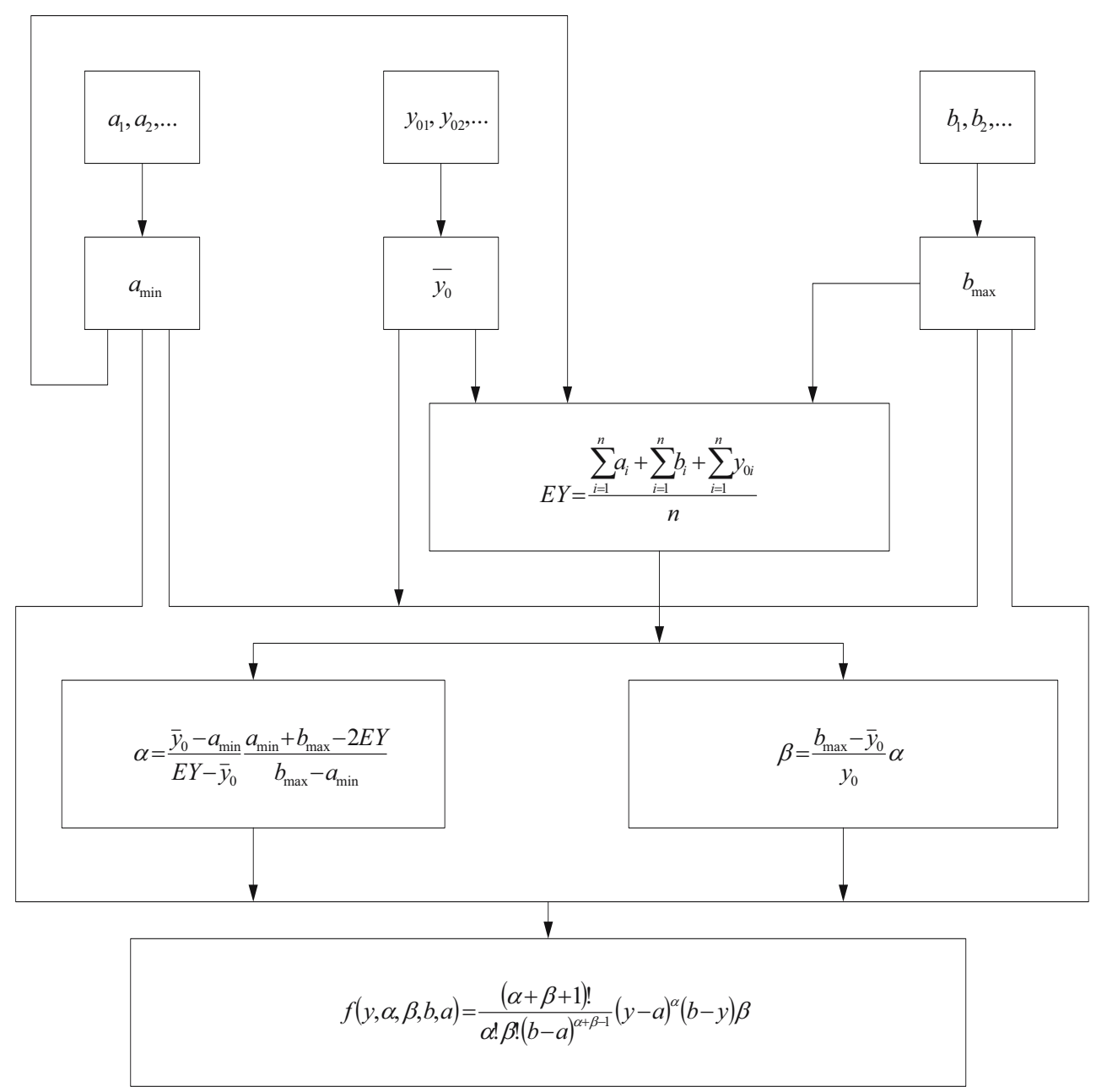

Fig 6. Flow chart for estimation of the parameters of beta distribution on the grounds of expert estimates.

The expert investigation procedure considers portraying of particular experts by means of so-called "personal" curve of subjective probability density for generating the estimates. The expected value of the estimate of the feature $\mathrm{Y}$ provided by a particular expert for a given situations is determined in the same way as for network methods (Bolding 1964) according to the formula:

$$
\mathrm{EY}_{0 i}=\frac{a_{i}+b_{i}+4 y_{o i}}{6}, \quad i=1,2, \ldots, n
$$


The remaining individual estimates $a_{i}, b_{i}, y_{o i}, i=1,2, \ldots, n$ serve for determining the characteristic parameters of the distribution, with the use of formulae (12) and (13).

For instance, to determine a probabilistic characteristics of operator availability a team of $n$ experts is nominated and each of them has to answer the following questions:

- What is the optimistic availability of the operator $: a_{l}=$ ?

- What is the pessimistic availability of the operator $\quad: b_{i}=$ ?

- What is the most likely availability of the operator $: y_{0 i=}$ ?

The set of estimates provided by the experts is analysed (Jaźwiński, Smalko 1996). In the entire data set, the following estimates are distinguished: optimistic - max $a$, max $b$; pessimistic - mina and $\min b$, and modal $y_{o}$. And the table below presents possible variants of classification of estimates provided by $(i=1,2, \ldots)$ experts.

\begin{tabular}{|l|l|c|l|}
\hline & \multicolumn{2}{|l|}{ PARAMETER ESTIMATION } & ESTIMATE \\
\hline $\mathrm{A}$ & $\min \left(y_{o i}-a_{i}\right)$ & $\max \left(b_{i}-y_{o i}\right)$ & PESIMISTIC \\
\hline $\mathrm{B}$ & $\min \left(y_{o i}-a_{i}\right)$ & $\max \left(b_{i}-y_{o i}\right)$ & MODERATELY PESIMISTIC \\
\hline $\mathrm{C}$ & $y_{o i}-a_{i}$ & $b_{i}-y_{o i}$ & MODERATE \\
\hline $\mathrm{D}$ & $\max \left(y_{o i}-a_{i}\right)$ & $\min \left(b_{i}-y_{o i}\right)$ & MODERATELY OPTIMISTIC \\
\hline $\mathrm{E}$ & $\max \left(y_{o i}-a_{i}\right)$ & $\min \left(b_{i}-y_{o i}\right)$ & OPTIMISTIC \\
\hline
\end{tabular}

The examples of curves shown in Fig. 7 represent outputs of particular experts, respectively:

$$
\begin{array}{ll}
\left\{\left[\left(\mathrm{a}_{\mathrm{i}}-\mathrm{y}_{\mathrm{oi}}\right) \downarrow 0\right]=(\mathrm{x} \downarrow 0)\right\} & \text {-pessimistic behaviour, } \\
\left.\left\{\left[\left(\mathrm{b}_{\mathrm{i}}-\mathrm{y}_{\mathrm{oi}}\right) \downarrow 0\right)\right]=(\mathrm{x} \rightarrow 1)\right\} & \text { - optimistic behaviour, and } \\
\left\{\left[\left(\mathrm{y}_{\mathrm{oi}}-\mathrm{a}_{\mathrm{i}}\right)\left(\mathrm{b}_{\mathrm{i}}-\mathrm{y}_{\mathrm{oi}}\right)\right]=(\mathrm{x} \rightarrow 1 / 2)\right\} & \text { - balanced behaviour. }
\end{array}
$$

The defined value employed for classification of experts as balanced ones in the expert team has a minimum value of the difference between the modal estimates, i.e. $\left|\bar{y}_{o}-y_{o i}\right| \rightarrow \min$. 

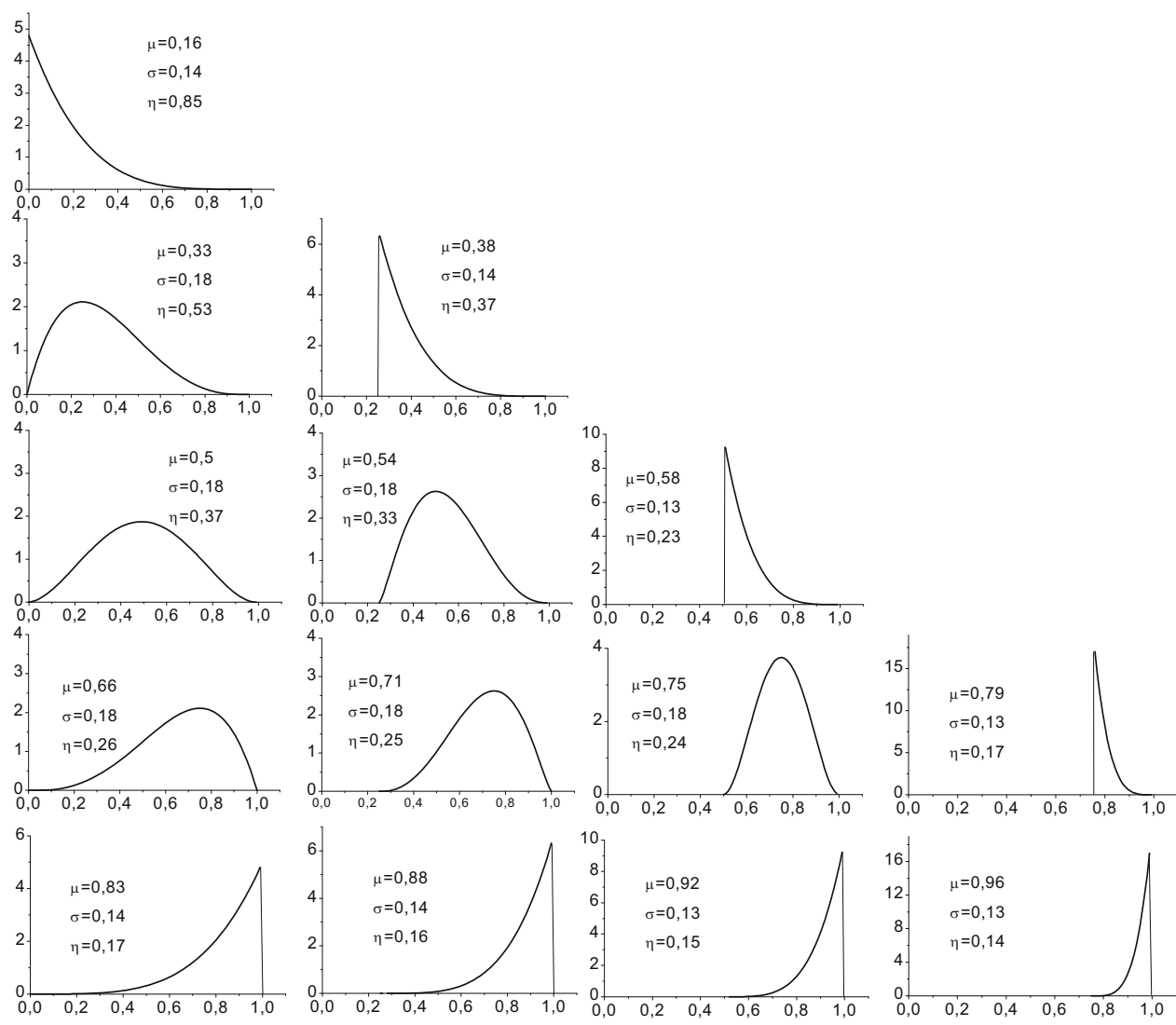

Fig. 7. Selected density curves that exemplify characteristics of the particular experts.

\section{Conclusion}

The beta distribution is recognized as one that belongs to the class of most flexible probability distributions bound at both its sides. This assumption results in realistic limitation of the given-phenomenon observation time to a certain finite interval $[a, b]$.

However, even if this bound is true various distribution curves are likely as these depend on the parameters $\alpha$ i $\beta$.

The advantages of the beta distribution presented in this paper permit us to recommend its use for estimating the reliability and safety of some class of plants/machines including the technical transport facilities.

In particular, the beta distribution is suitable under uncertainty conditions and in situations where those events occur which are rather rare in practice. 
By taking a possible change in the modal value position within the distribution span it can be stated that this distribution is particularly suitable for determining the subjective probability of operations events.

It should be noted that the use expert method requires a desirable variety of expert behaviours to prove, among other things, that the estimates are produced independently.

\section{References}

[1] Bobrowski D., Modele i metody matematyczne teorii niezawodności [Mathematical Methods and Models in Reliability Theory]. WNT, Warszawa 1985, (pp. 126-127).

[2] Jaźwiński J., Smalko Z., Wykorzystanie rozkładu trójkątnego w modelowaniu bezpieczeństwa systemu transportowego. Materiały VI Sympozjum Bezpieczeństwa Systemów [Using a Triangular Distribution for Model-building for Transport System Safety Purposes. Proceedings of VI System Safety Symposium], Kiekrz 1996 r.

[3] Jaźwiński J., Smalko Z., Żurek J., The Monte Carlo method as applied to determine subjective probability of dangerous events in air transport systems, with expert method engaged, Proceedings of Materials International Conference Monte Carlo Methods, Monte Carlo 2000r

[4] Nill R.D., Clayton J.R., Reliability Handbook, Mc Graw-Hill Book Company, New York, London, Sydney 1966 r.(tom 1,str.165-168).

[5] Bolding K.E., System Engineering Handbook, Mc Graw Hill Book Company, New York, London, Sydney 1964r.(str.569-570).

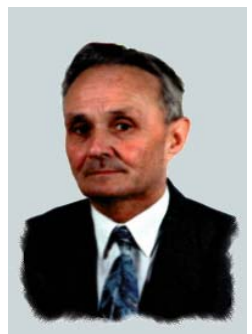

Prof. Jerzy JAŹWIŃSKI DSc. Eng. (born in1927, Torczyn). Scientific Worker of Air Force Institute of Technology. Field of science: aviation transport, reliability, safety. Author and co-author of over 200 publications and books. Co-organizer of conferences: "Reliability in transport", "Safety of the systems", "Safety and Reliability KONBiN", "Annual winter schools on reliability". Activity in the following organizations: Polish Cybernetics Society, Committee of Transport of Polish Academy of Sciences, Committee of Mashine Building of Polish Academy of Sciences, Team of Reliability of the Section of Exploitation of the Committee of Mashine Building (Polish Academy of Sciences), Committee of Scientific Investigations - Team of Transport, Society of Reliability and Safety.

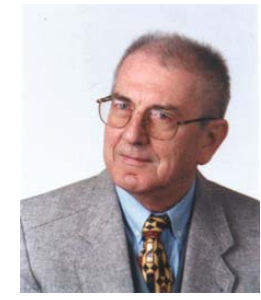

Prof. Zbigniew SMALKO DSc. Eng, professor of the Air Force Institute of Technology, Warszawa, as well as the University of Technology, Faculty of Transport. Specialist in reliability safety and maintainability of technical transport systems, operation problems of transport systems and devices. Author and co-author of more then 200 scientific publications. Member of: Polish Academy of Science (PAN) - Transport Committee, PTBiN, ERN SAFERLENET, ETNiŚT; Editor in Chief of Archives of Transport, Chair of Winter Schools of Reliability PAN. Organisator and member of several scientific and programme committees of international and national conferences and symposiums. 